\title{
Dermatomycosis due to Chrysosporium anamorph Nannizziopsis vriesii: a fungal pathogen of green iguanas (Iguana iguana) in Tabriz, Iran
}

AMSTERDAM

30 JUNE - 4 JULY 2018

\section{Farzad Katiraee, Minoo Soltani, Seyedeh Yasaman Kouchak Kosari}

\author{
${ }^{1}$ Department of Pathobiology, Faculty of Veterinary Medicine, University of Tabriz, \\ Tabriz, Iran
}

Objectives: Iguana iguana is one of the newly imported exotic animals which has been observed with increasing in Iran. Despite the popularity of iguana in Iran, information about their diseases is scarce. We describe the clinical, mycological, and molecular findings in green iguanas (Iguana iguana) affected with dermatomycosis in two cases in Tabriz, Azerbaijan, Iran.

Methods: the animals referred to Faculty of Veterinary Medicine, Tabriz, Iran with Chronic seborrheic and ulcerative dermatitis located the body. Clinical samples were collected from the scales of skin lesions and cultured on SC and SCC. Also direct microscopic examination was done by $\mathrm{KOH} 10 \%$. After growth of fungal species on media culture molecular diagnosis were done by ITS sequencing method, as using Primers were amplified and sequenced. Sequenced data compare with database (www.pubmed.com ) and fungal species were identified.

Results:

All two iguanas were definitively diagnosed with dermatomytosis using phenotypic and molecular diagnostic methods. Microscopic examination of fungal culture revealed fungal elements as Chrysosporium species. PCR sequencing showed that two diagnosed iguanas had the dermatomycosis due to Chrysosporium anamorph Nannizziopsis vriesii. We didn't isolate any other dermatophytes or saprophyte fungal species from lesions.

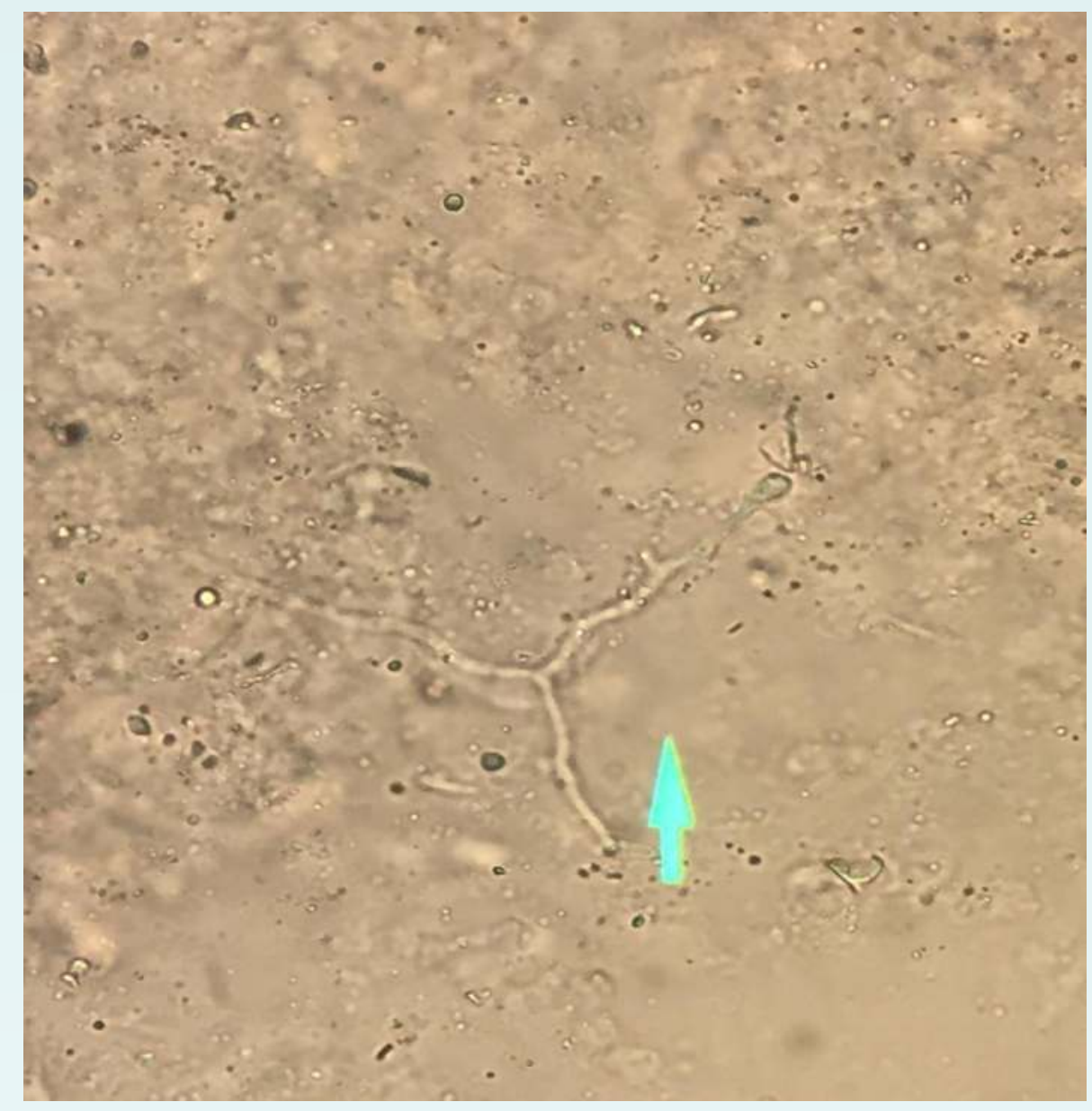

Fungal hyphae on DME with $\mathrm{KOH} 10 \%$
Conclusion: Chrysosporium anamorph Nannizziopsis vriesii is a recent pathogen associated with infections in lizards, snakes, and crocodilians. This is the first report of the Chrysosporium anamorph Nannizziopsis vriesii causing disease in Iguana iguana in Iran. Also due to similarity of Colony and microscopic morphology of Chrysosporium to some dermatophytes species, molecular diagnosis methods should be considered.

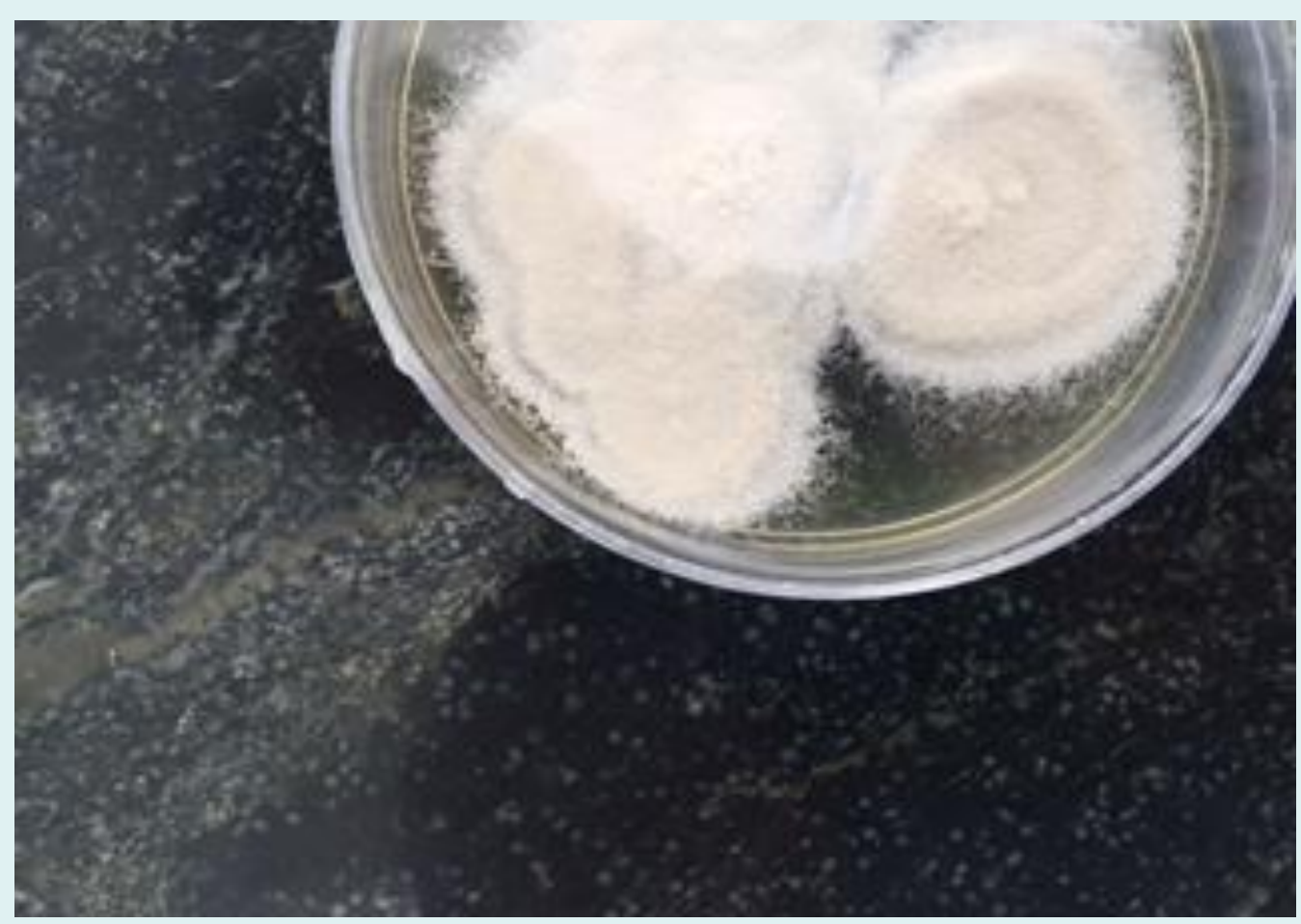

\section{Colony morphology of Nannizziopsis vriesii on SDA after one weeks.}

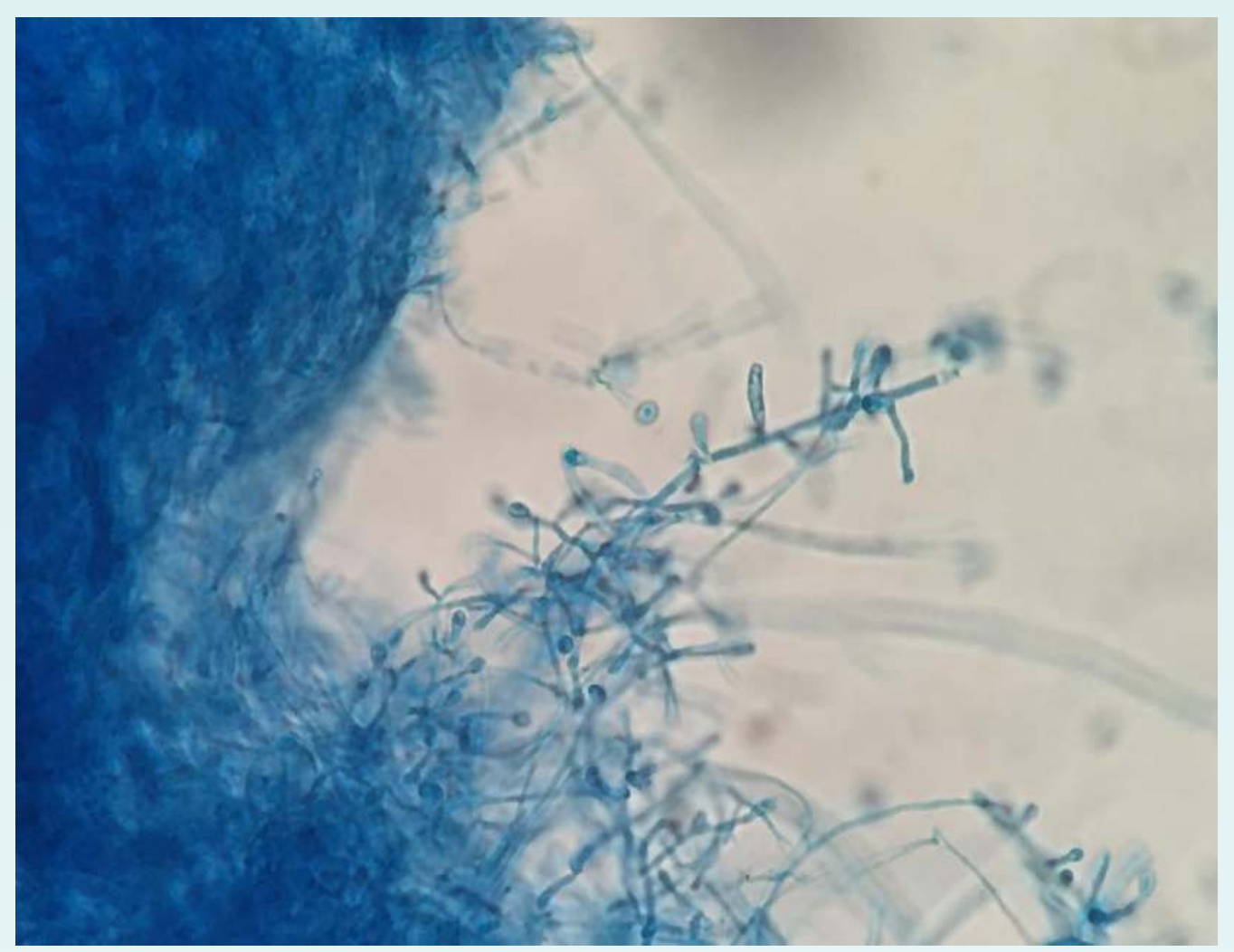

\section{Microscopic feature of Nannizziopsis vriesii}

